\title{
Use of Chronic Care Management Codes for Medicare Beneficiaries: a Missed Opportunity?
}

\author{
Rebekah L. Gardner, MD ${ }^{1,2}$, Rouba Youssef, PhD², Blake Morphis, BS ${ }^{2}$, Alyssa DaCunha, MPH², \\ Kimberly Pelland, $\mathrm{MPH}^{2}$, and Emily Cooper, $\mathrm{MPH}^{2}$
}

'Department of Medicine, Alpert Medical School of Brown University, Providence, RI, USA; ${ }^{2}$ Healthcentric Advisors, Providence, RI, USA.

\begin{abstract}
BACKGROUND: Physicians spend significant time outside of regular office visits caring for complex patients, and this work is often uncompensated. In 2015, the Centers for Medicare \& Medicaid Services (CMS) introduced a billing code for care coordination between office visits for beneficiaries with multiple chronic conditions.
\end{abstract}

OBJECTIVE: Characterize use of the Chronic Care Management (CCM) code in New England in 2015.

DESIGN: Retrospective observational analysis.

PARTICIPANTS: All Medicare fee-for-service beneficiaries in New England continuously enrolled in Parts A and B in 2015.

INTERVENTION: None.

MAIN MEASURES: The primary outcome was the number of beneficiaries with a CCM claim per 1000 eligible beneficiaries. Secondary outcomes included the total number of CCM claims, total reimbursement, mean number of claims per beneficiary, and beneficiary characteristics independently associated with receiving $\mathrm{CCM}$ services.

KEY RESULTS: Of the more than two million Medicare fee-for-service beneficiaries in New England, almost 1.7 million were potentially eligible for CCM services. Among eligible beneficiaries, $10,951(0.65 \%)$ had a CCM claim in 2015. Massachusetts had the highest penetration of CCM use (9.40 claims per 1000 eligible beneficiaries); Vermont had the lowest (0.54 claims per 1000 eligible beneficiaries). Mean reimbursement per physician was $\$ 1745.98$. Age, race/ethnicity, dual-eligible status, income, number of chronic conditions, and state of residence were associated with receiving CCM services in an adjusted model.

CONCLUSIONS: The CCM code is likely underutilized in New England; the program may therefore not be achieving its intended goal of encouraging consistent, team-based chronic care management for Medicare's most complex beneficiaries. Or practices may be foregoing reimbursement for care coordination that they are already providing. Recently implemented revisions may improve uptake of CCM services; it will be important to compare our results with future utilization.

Electronic supplementary material The online version of this article (https://doi.org/10.1007/s11606-018-4562-z) contains supplementary material, which is available to authorized users.

Received September 28, 2017

Revised March 12, 2018

Accepted June 28, 2018

Published online July 20, 2018
KEY WORDS: chronic care management; Medicare; primary care; care coordination.

$\mathrm{J}$ Gen Intern Med 33(11):1892-8

DOI: $10.1007 / \mathrm{s} 11606-018-4562-\mathrm{z}$

(c) Society of General Internal Medicine 2018

\section{INTRODUCTION}

Physicians and their staff spend significant time outside of regular office visits caring for complex patients. ${ }^{1-3}$ This work is critically important for coordinating care and is expected and valued by patients, ${ }^{4,5}$ but it is time-consuming ${ }^{6,7}$ and historically has not been compensated through traditional Evaluation and Management (E/M) codes.

In 2015, the Centers for Medicare \& Medicaid Services (CMS) introduced a billing code that allowed physicians to bill for care coordination between office visits for beneficiaries with two or more chronic conditions. The chronic care management (CCM) services code requires at least $20 \mathrm{~min}$ of clinical staff time directed by a physician each month, with reimbursement of about $\$ 40$ per beneficiary per month. ${ }^{8,9}$ Medicare estimates that only half a million Medicare beneficiaries received CCM services ${ }^{10}$ in 2015, the first year the CCM code was available. Physicians reported that they found it difficult to implement the infrastructure, health information technology, and documentation requirements needed to use the code efficiently and successfully. ${ }^{10,11}$

In response to this feedback, CMS modified the original CCM code requirements in 2017 to ease their use (e.g., allowing faxing of care plans in addition to electronic transmission) and added codes for more complex patients. ${ }^{12}$ However, use of the CCM code has not been well described, making it challenging to assess progress in response to the recent changes. This study aims to fill this important gap by characterizing use of the CCM code for Medicare fee-for-service (FFS) beneficiaries in New England in 2015. These results can inform future revisions to the CCM code and implementation of similar codes to better support management of complex, chronically ill patients by easing reimbursement for care coordination services. 


\section{METHODS}

\section{Participants and Setting}

The study population includes all Medicare FFS beneficiaries in New England (Connecticut, Maine, Massachusetts, New Hampshire, Rhode Island, and Vermont) who were continuously enrolled in Parts A and B in 2015. Beneficiaries who died in 2015 are included up until their date of death if they died after January 31, 2015.

\section{Data Sources}

We used the following data sources: Medicare FFS Part A and Part B claims data (2013-2015), Medicare enrollment data (2015), and US Census Bureau data for ZIP Code tabulation areas (2014). Healthcentric Advisors, the New England Medicare Quality Innovation Network-Quality Improvement Organization, has access to Medicare claims data under a CMS data use agreement that allows use of these data to evaluate improvement in care quality. Institutional Review Board review is not required in these circumstances, per Healthcentric Advisors' policy.

\section{CCM Code Goals and Requirements}

CMS has outlined several goals for the CCM program. ${ }^{13}$ For patients, objectives include improved health outcomes, better care coordination including use of a comprehensive care plan, higher satisfaction, and a team to provide support between office visits. For physicians, CMS aims to recognize the time, effort, and costs for care coordination; to support patient adherence and decrease unplanned utilization; and to help physicians sustain their practices and expand their panels.

Beneficiaries are potentially eligible for the CCM code (99490) if they have two or more chronic conditions that are expected to last at least 12 months or until death and if these conditions place them "at significant risk of death, acute exacerbation/decompensation, or functional decline" ${ }^{8}$ The 2015 CCM requirements stated that services must be initiated during a comprehensive E/M visit, an Annual Wellness Visit, or an Initial Preventive Physical Examination. Physicians or their staff must develop and follow a patient-centered care plan and provide regular follow-up by a designated member of the care team. Additionally, CMS requires physicians to have a certified electronic health record (EHR) to bill the CCM code. Only one physician can bill a CCM code for a beneficiary each month.

\section{Creation of the Eligible Population}

To compare beneficiaries who received CCM services with those who did not, we created a population of beneficiaries potentially eligible to receive CCM services using the following approach:

First, to account for the office visit required to initiate $\mathrm{CCM}$ services in 2015, we limited the pool of beneficiaries to those with an outpatient claim from January 1, 2014, to June 30, 2015 , and with at least one of the following types of E/M codes: office or other outpatient services, preventive medicine services, Annual Wellness Visit, and Initial Preventive Physical Exam (see Online Appendix Table 1 for a list of the included codes). We chose the 2014-2015 timeframe because initiating CCM services requires an outpatient visit within the prior year.

Second, we created a pool of beneficiaries with two or more chronic conditions, based on Medicare FFS Part A and Part B claims data for January 1, 2013, to June 30, 2015. CMS does not specify which chronic conditions qualify beneficiaries for use of CCM services. We chose diagnoses based on those provided as examples in the CMS factsheet on the CCM codes, ${ }^{8}$ included in the Chronic Conditions Data Warehouse diagnoses, ${ }^{14}$ identified by the Multiple Chronic Conditions Working Group, ${ }^{15}$ and/or included in a publication about multiple chronic conditions among Medicare beneficiaries. ${ }^{16}$

Using these references, we selected the following chronic conditions for inclusion in this study: acute myocardial infarction, Alzheimer's disease and related dementias, anemia, arthritis (osteoarthritis and rheumatoid arthritis), asthma, atrial fibrillation, autism spectrum disorders, benign prostatic hypertrophy, cancer (breast, colorectal, prostate, lung, and endometrial), cataracts, chronic kidney disease, chronic obstructive pulmonary disease (COPD), depression, diabetes, glaucoma, heart failure, chronic viral hepatitis, hip or pelvic fracture, HIV, hyperlipidemia, hypertension, hypothyroidism, ischemic heart disease, osteoporosis, schizophrenia, stroke or transient ischemic attack, and substance use disorder.

Most ICD-9 and ICD-10 codes were available through the Chronic Conditions Data Warehouse. ${ }^{14}$ For those that were not, we looked to published studies on similar populations ${ }^{17-}$ ${ }^{28}$ and mapped equivalent diagnoses between ICD-9 and ICD10 (Online Appendix Table 2). When creating the eligible population, we looked at all Part A and Part B claims for each beneficiary from January 1, 2013, to June 30, 2015, and included all conditions that matched the diagnosis codes in Online Appendix Table 2. We also performed a sensitivity analysis in which we removed Part B claims that were associated with services provided at walk-in retail health clinics, urgent care facilities, or emergency departments (place of service codes 17,20 , and 23 , respectively), as well as those associated with radiology or laboratory studies. We performed this sensitivity analysis because diagnosis codes associated with claims for diagnostic tests and episodic care (such as that provided in urgent care centers and emergency departments) may less reliably predict the true prevalence of certain diagnoses among our population.

We included beneficiaries who met the criteria for both the required office visit and the two chronic conditions, regardless of age. We did not attempt to limit the population to beneficiaries seen in practices with certified EHRs. We then divided the eligible population into beneficiaries who had a CCM code in the claims file for 2015 and those who did not. 


\section{Data Analysis}

We conducted a retrospective observational analysis. Our primary outcome was the number of beneficiaries with a CCM claim per 1000 eligible beneficiaries in each New England state in 2015. Secondary outcomes included the total number of CCM claims in each state in 2015, the total reimbursement for those claims, the mean number of CCM claims billed per beneficiary, the number of physicians billing CCM services, and the mean reimbursement per physician, among physicians billing CCM services.

In a bivariate analysis, we compared characteristics of eligible beneficiaries who had a CCM claim with those who did not, using chi-square tests. Using logistic regression, we identified variables associated with a beneficiary having any CCM claim. We adjusted for beneficiary-level measures in the regression model including beneficiary age (categorized into 0 18 years, 19-64 years, and $>64$ years), sex, race/ethnicity (Asian, Black, Hispanic, White, and other), whether the beneficiary was dually eligible for Medicare and Medicaid, the number of chronic conditions from Online Appendix Table 2 captured in the 2013-2015 claims data (0-3, 4-6, and >6), and state of residence. We used 2014 US Census Bureau estimates to identify the median household income for each beneficiary's ZIP Code tabulation area of residence. After examining the distribution of median household income across New England, we stratified the ZIP Code-level median income variable into three levels: low income $(<\$ 47,700)$, middle income $(\$ 47,700$ to $\$ 71,550)$, and high income $(>\$ 71,550)$. We also adjusted for the presence of specific diagnoses that were commonly submitted with CCM claims (diabetes, ischemic heart disease, heart failure, and COPD).

\section{Role of the Funding Source}

This study was supported by a CMS contract awarded to Healthcentric Advisors. CMS reviewed the manuscript and provided comments, but did not have any role in the design and conduct of the study; collection, management, analysis, or interpretation of the data; or preparation or approval of the manuscript.

\section{RESULTS}

Of the more than two million Medicare FFS beneficiaries in New England in 2015, almost 1.7 million were eligible for CCM services according to the criteria used for this study (Table 1). Among eligible beneficiaries, 10,951 (0.65\%) had any CCM claim in 2015, translating to a New England-wide rate of 5.09 beneficiaries with CCM claims per 1000 eligible beneficiaries in 2015 (Table 1). We noted considerable variation across the New England states in use of CCM services: Massachusetts had the highest penetration of CCM use (9.40 claims per 1000 eligible beneficiaries), and Vermont had the lowest ( 0.54 claims per 1000 eligible beneficiaries).
The six New England states saw a total of 42,362 CCM claims in 2015. Among beneficiaries with a CCM claim, the mean number of claims per beneficiary was 3.52 (SD 2.60) (Table 2). Maine had the highest number of mean claims per beneficiary at 6.21 (SD 2.78) and New Hampshire had the lowest (2.43 [SD 1.97]). The total reimbursement for CCM claims in New England was $\$ 1,354,882$ in 2015 , with more than half going to Massachusetts $(\$ 853,863)$. Mean reimbursement per physician, among physicians billing for CCM services, was $\$ 1745.98$ in 2015 . This also varied by state, with Vermont averaging \$242.48 per physician and Massachusetts averaging \$2954.54 (Table 2). Overall, 776 physicians in New England billed for CCM services in 2015, ranging from a total of 37 physicians in Vermont to 289 in Massachusetts.

Bivariate analyses revealed that, compared to those who did not have a CCM claim, greater proportions of the 10,951 eligible beneficiaries with CCM claims were 65 years or older (90.1 vs $80.8 \%$ without a CCM claim, $p<0.0001$ ), were White (94.1 vs $90.3 \%$ without a CCM claim, $p<0.0001$ ), and had more than six chronic conditions (65.3 vs $46.6 \%$ without a CCM claim, $p<0.0001$ ) (Table 3 ).

Compared to those with a CCM claim, greater proportions of beneficiaries without a CCM claim were Black (4.1 vs $2.5 \%$ with a CCM claim, $p<0.0001)$ and were dually eligible for Medicare and Medicaid (24.3 vs $17.4 \%$ with a CCM claim, $p<0.0001$ ) (Table 3). There were no differences between the groups with regard to gender $(57.3 \%$ of those with a CCM claim were women vs $57.0 \%$ without a claim, $p=0.54$ ).

In the adjusted model, age, race/ethnicity, dual-eligible status, income, number of chronic conditions, presence of selected diagnoses, and state of residence remained significantly associated with receiving CCM services (Fig. 1). Older age (AOR $1.71,95 \%$ CI 1.59 to 1.83 ; 65 years or older compared with younger than 65 ) and the presence of COPD (AOR 1.05, 95\% CI 1.00 to 1.10; compared with no COPD) or ischemic heart disease (AOR 1.06, 95\% CI 1.01 to 1.11; compared with no ischemic heart disease) were associated with higher odds of having a CCM claim. Dual-eligible status (AOR 0.75, 95\% CI 0.71 to 0.79 ; compared with not dually eligible), fewer chronic conditions (AOR $0.59,95 \%$ CI 0.57 to $0.62 ; 4$ to 6 chronic conditions compared to more than 6), and being Black, Asian, or Hispanic (AOR 0.51, 95\% CI 0.46 to 0.58 ; AOR 0.32, 95\% CI 0.23 to 0.45 ; AOR $0.47,95 \%$ CI 0.37 to 0.59 ; respectively, compared with White) were associated with lower odds of having a CCM claim. Beneficiaries residing in ZIP Codes with both the lowest median annual household income $(<\$ 47,700)$ and the highest median annual household income $(>\$ 1,550)$ had lower odds of receiving CCM services compared to those in the middle-income group (AOR 0.77, 95\% CI 0.73 to 0.81 ; AOR $0.41,95 \%$ CI 0.39 to 0.43 ; respectively). Living in Massachusetts was also positively associated with receiving $\mathrm{CCM}$ services in the adjusted model. A sensitivity analysis that removed claims with certain place of service codes, as well as radiology and laboratory claims, produced results similar to those of the primary analysis. 
Table 1 Medicare Fee-for-Service Beneficiaries with a CCM Claim in 2015, by State

\begin{tabular}{|c|c|c|c|c|c|}
\hline State & $\begin{array}{l}\text { Total } \\
\text { beneficiaries }\end{array}$ & $\begin{array}{l}\text { Number } \\
\text { of eligible } \\
\text { beneficiaries }\end{array}$ & $\begin{array}{l}\text { Number of eligible } \\
\text { beneficiaries with } \\
\text { CCM claims }\end{array}$ & $\begin{array}{l}\text { Number of beneficiaries } \\
\text { with CCM claims per } \\
1000 \text { beneficiaries }\end{array}$ & $\begin{array}{l}\text { Number of beneficiaries } \\
\text { with CCM claims per } \\
1000 \text { eligible beneficiaries }\end{array}$ \\
\hline All New England & $2,153,230$ & $1,691,803$ & 10,951 & 5.09 & 6.47 \\
\hline Connecticut & 467,811 & 374,990 & 2314 & 4.95 & 6.17 \\
\hline Maine & 236,559 & 175,444 & 713 & 3.01 & 4.06 \\
\hline Massachusetts & 954,867 & 770,432 & 7244 & 7.59 & 9.40 \\
\hline New Hampshire & 242,448 & 183,498 & 215 & 0.89 & 1.17 \\
\hline Rhode Island & 131,202 & 99,187 & 417 & 3.18 & 4.20 \\
\hline Vermont & 120,343 & 88,252 & 48 & 0.40 & 0.54 \\
\hline
\end{tabular}

CCM, chronic care management

\section{DISCUSSION}

We found that few Medicare beneficiaries in New England received CCM services in 2015, despite a large population of patients who were likely eligible. We also noted disparities in receipt of CCM services among different beneficiary populations, as well as variation in uptake across the six New England states, even after controlling for patient characteristics. These findings suggest that the CCM code, as currently implemented, is underutilized by physicians. Patients with complex chronic conditions may be missing out on high-quality, team-based care in between office visits, and practices may be foregoing reimbursement for care coordination that they are already providing.

Physicians and their practices may be eschewing use of the CCM code for a variety of reasons, including lack of awareness that reimbursement for chronic disease management in between office visits is available. ${ }^{29}$ Among those aware of the code, the most widely reported barrier is that the infrastructure, health information technology, and documentation requirements are overly burdensome. ${ }^{10,30-32}$ Practices face many other competing initiatives $^{33}$ in their practice environment and may not have the time or resources to explore implementation of CCM billing. Practices may have too few Medicare patients to make implementation worthwhile. A study estimated that a practice would need to enroll at least 131 Medicare patients to recoup its costs if it hired a full-time registered nurse to provide CCM services. ${ }^{34}$ For the average primary care physician in the USA, 131 Medicare patients represent more than a quarter of the Medicare patients in their panel, ${ }^{34}$ which may not be a realistic target.

We found variation in use of the CCM code across the different New England states. Overall, physicians in the Southern New England states billed more CCM claims than the Northern New England states, even when accounting for differences in the eligible populations. Our findings may echo regional utilization patterns, with Southern New England states routinely demonstrating higher utilization of healthcare services than Northern New England states. ${ }^{35-37}$ They may also reflect regional differences in technology, staffing, or membership in larger healthcare systems. Notably, Massachusetts has experienced substantial healthcare industry consolidation, ${ }^{38}$ which may facilitate delivery of CCM services due to improved infrastructure.

Our work confirms preliminary CMS analyses that showed that older patients and those with more chronic conditions were more likely to receive CCM services. ${ }^{10}$ These patients tend to visit their physician more frequently and to require more intensive care coordination from the practice between visits. Given differences in healthcare utilization between men and women, ${ }^{39-41}$ it was interesting to note that gender was not associated with receiving CCM services in this analysis. Race/ethnicity, however, was associated with receipt of CCM services. In analyses controlled for patient characteristics, White beneficiaries were more likely to have a CCM claim than Black, Asian, or Hispanic

Table 2 CCM Claims and Reimbursement in 2015, by State

\begin{tabular}{|c|c|c|c|c|c|c|c|}
\hline$\overline{\text { State }}$ & $\begin{array}{l}\text { Total } \\
\text { number } \\
\text { of CCM } \\
\text { claims }\end{array}$ & $\begin{array}{l}\text { Mean (SD) } \\
\text { number of } \\
\text { claims per } \\
\text { beneficiary }\end{array}$ & $\begin{array}{l}\text { Median } \\
\text { number of } \\
\text { claims per } \\
\text { beneficiary }\end{array}$ & $\begin{array}{l}\text { Range of } \\
\text { number of } \\
\text { claims per } \\
\text { beneficiary }\end{array}$ & $\begin{array}{l}\text { Total } \\
\text { reimbursement } \\
\text { for CCM claims (\$) }\end{array}$ & $\begin{array}{l}\text { Total number } \\
\text { of physician } \\
\text { billing CCM } \\
\text { services }\end{array}$ & $\begin{array}{l}\text { Mean } \\
\text { reimbursement } \\
\text { per physician (\$) }\end{array}$ \\
\hline All New England & 42,362 & $3.52(2.60)$ & 3 & $1-22$ & $1,354,882$ & 776 & 1745.98 \\
\hline Connecticut & 9275 & $3.64(2.75)$ & 3 & $1-22$ & 301,438 & 185 & 1629.39 \\
\hline Maine & 4984 & $6.21(2.78)$ & 7 & $1-12$ & 129,512 & 64 & 2023.63 \\
\hline Massachusetts & 25,897 & $3.28(2.40)$ & 3 & $1-17$ & 853,863 & 289 & 2954.54 \\
\hline New Hampshire & 643 & $2.43(1.97)$ & 2 & $1-11$ & 20,149 & 132 & 152.65 \\
\hline Rhode Island & 1277 & $2.81(1.82)$ & 2 & $1-8$ & 40,948 & 69 & 593.46 \\
\hline Vermont & 286 & $4.61(3.97)$ & 3 & $1-13$ & 8972 & 37 & 242.48 \\
\hline
\end{tabular}


Table 3 Characteristics of Eligible Medicare Fee-for-Service Beneficiaries in 2015, by Presence of a CCM Claim $(N=1,691,803)$

\begin{tabular}{|c|c|c|c|}
\hline Characteristic & $\begin{array}{l}\text { With a CCM claim } \\
n(\%)\end{array}$ & $\begin{array}{l}\text { Without a CCM claim } \\
n(\%)\end{array}$ & $p$ value \\
\hline Eligible beneficiaries & $10,951(0.65)$ & $1,680,852(99.35)$ & $p<0.0001$ \\
\hline \multicolumn{3}{|l|}{ Age } & $p<0.0001$ \\
\hline $0-18$ years & $0(0)$ & $53(0)$ & \\
\hline $19-64$ years & $1088(9.94)$ & $323,670(19.26)$ & \\
\hline$>64$ years & $9863(90.06)$ & $1,357,038(80.80)$ & \\
\hline Female & $6274(57.29)$ & $958,123(57.00)$ & $p=0.54$ \\
\hline \multicolumn{3}{|l|}{ Race/ethnicity } & $p<0.0001$ \\
\hline Asian & $37(0.34)$ & $16,915(1.01)$ & \\
\hline Black & $275(2.51)$ & $68,376(4.07)$ & \\
\hline Hispanic & $76(0.69)$ & $26,545(1.58)$ & \\
\hline White & $10,309(94.14)$ & $1,518,256(90.33)$ & \\
\hline Other & $117(1.07)$ & $22,565(1.34)$ & \\
\hline Dually eligible for Medicare and Medicaid & $1900(17.35)$ & $407,770(24.26)$ & $p<0.0001$ \\
\hline \multicolumn{3}{|l|}{ Median household income* } & $p<0.0001$ \\
\hline$<\$ 47,700$ & $2040(18.63)$ & $359,866(21.41)$ & \\
\hline$\$ 47,700$ to $\$ 71,550$ & $5530(50.50)$ & $617,241(36.72)$ & \\
\hline$>\$ 71,550$ & $3381(30.87)$ & $703,745(41.87)$ & \\
\hline \multicolumn{3}{|l|}{ Number of chronic conditions ${ }^{\dagger}$} & $p<0.0001$ \\
\hline $0-3$ & $438(4.00)$ & $225,209(13.40)$ & \\
\hline $4-6$ & $3365(30.73)$ & $672,664(40.02)$ & \\
\hline$>6$ & $7148(65.27)$ & $789,297(46.58)$ & \\
\hline \multicolumn{4}{|l|}{ Presence of selected diagnoses } \\
\hline COPD & $3184(29.07)$ & $387,868(23.08)$ & $p<0.0001$ \\
\hline Diabetes & $3938(35.96)$ & $522,848(31.11)$ & $p<0.0001$ \\
\hline Heart failure & $2197(20.06)$ & $237,805(14.15)$ & $p<0.0001$ \\
\hline Ischemic heart disease & $3960(36.16)$ & $445,085(26.48)$ & $p<0.0001$ \\
\hline
\end{tabular}

Chi-square tests were used to calculate $p$ values. Beneficiaries were considered eligible for CCM services in this analysis if they had two or more prespecified chronic conditions and a qualifying office visit. CCM, chronic care management; COPD, chronic obstructive pulmonary disease

Income data represent median household income for the beneficiary's ZIP Code tabulation area of residence (from 2014 US Census Bureau data) ${ }^{\dagger}$ Chronic conditions consisted of the following diagnoses: acute myocardial infarction, Alzheimer's disease and related dementias, anemia, arthritis (osteoarthritis and rheumatoid arthritis), asthma, atrial fibrillation, autism spectrum disorders, benign prostatic hypertrophy, cancer (breast, colorectal, prostate, lung, and endometrial), cataracts, chronic kidney disease, chronic obstructive pulmonary disease (COPD), depression, diabetes, glaucoma, heart failure, chronic viral hepatitis, hip or pelvic fracture, HIV, hyperlipidemia, hypertension, hypothyroidism, ischemic heart disease, osteoporosis, schizophrenia, stroke or transient ischemic attack, and substance use disorder

Male

Age $\geq 65$

Asian (vs White)

Black (vs White)

Hispanic (vs White)

Dually eligible

High income (vs medium)

Low income (vs medium)

$0-3$ chronic conditions (vs $>6$ )

4-6 chronic conditions (vs >6)

COPD diagnosis

Diabetes diagnosis

Heart failure diagnosis

Cardiac ischemia diagnosis

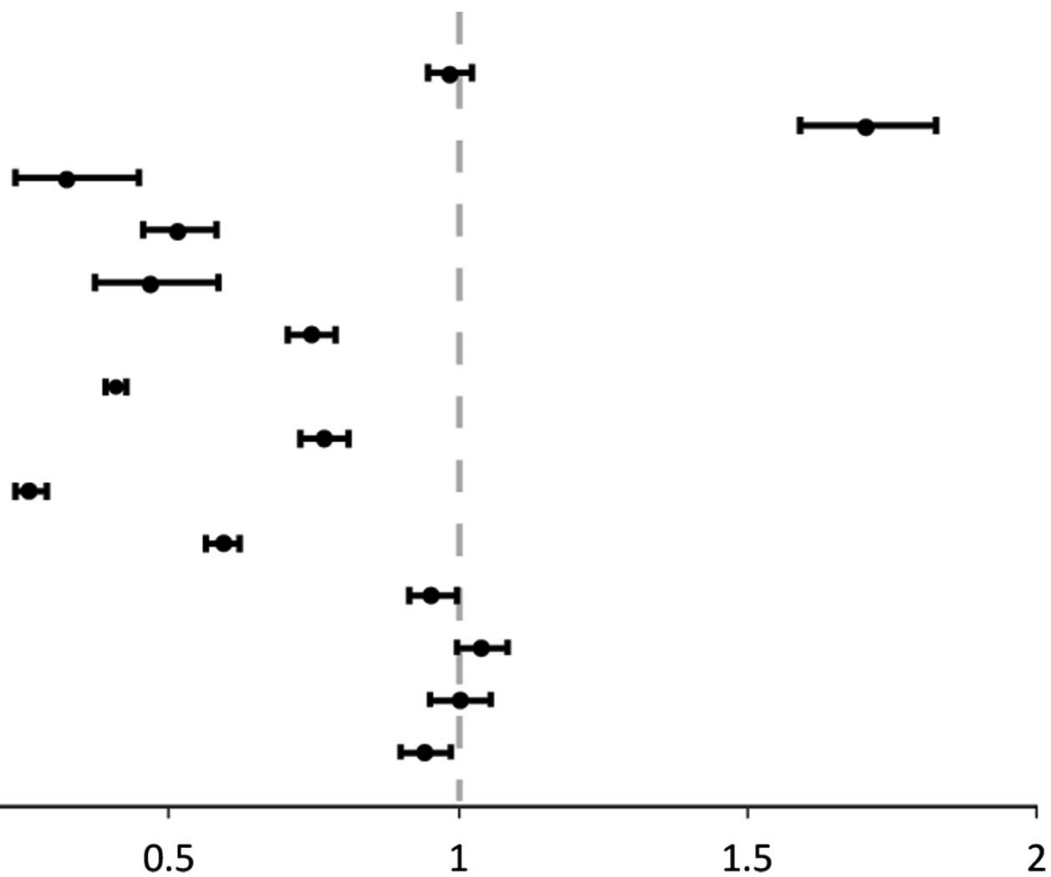

Figure 1 Forest plot of the fully adjusted logistic regression model assessing the odds of receiving CCM services among different Medicare feefor-service populations. Model is adjusted for age, sex, race/ethnicity, whether dually eligible for Medicare and Medicaid, median household income for the beneficiary's ZIP Code tabulation area of residence (from 2014 US Census Bureau data), number of chronic conditions, presence of selected diagnoses, and state of residence. CCM chronic care management, COPD chronic obstructive pulmonary disease. 
beneficiaries. This disparity may be present because nonWhite patients are more likely to be cared for by practices with fewer resources; ${ }^{42,43}$ implementation requirements may be particularly challenging in these settings. Or it may reflect differences in healthcare access or use overall among patients of different races and ethnicities. ${ }^{44}$ Despite having higher healthcare utilization generally, ${ }^{45}$ beneficiaries dually eligible for Medicare and Medicaid in this study were also less likely to receive CCM services. It is not yet clear if making these codes easier to implement by revising the requirements will increase their use for non-White beneficiaries and dually eligible beneficiaries.

The study's strengths include the large sample size and the ability to capture every CCM claim in the region in 2015. Limitations include the potential lack of generalizability to other regions of the country with different practice patterns. Additionally, we may have overestimated the population of eligible beneficiaries because we likely included patients whose physicians cannot bill the CCM code (e.g., because they do not have a certified EHR or participate in payment models that preclude use of these codes). However, beneficiaries with multiple chronic conditions often see many different physicians throughout the year, ${ }^{46}$ and any one of those could potentially have billed for CCM services. Conversely, we may have underestimated the eligible population because we did not include all possible diagnoses that may have prompted use of the CCM code in practice. We attempted to mitigate this limitation by including a wide array of diagnoses. Last, we are only able to control for variables present in claims data. Specifically, we are not able to include physician or practice characteristics in the model; a qualitative study found that practice size and ownership characteristics may affect the ability to provide and bill for CCM services. ${ }^{47}$

In summary, use of the CCM code in New England was low in 2015 , and the CCM program was likely underutilized by physicians and beneficiaries, perhaps due to lack of awareness or perceived or true implementation barriers. The program, as originally conceived and implemented in 2015 , is apparently not achieving its intended goal of encouraging consistent, team-based chronic care management for Medicare's most complex beneficiaries. There was variation in uptake across the six states, which suggests opportunities to learn from physicians and practices that successfully provide and bill for CCM services. ${ }^{11,47}$ Additionally, certain Medicare beneficiary populations were less likely to have CCM claims than others, which should prompt efforts to support wider use of these services, particularly in practices with limited resources. Recently implemented revisions to the program may improve uptake of CCM services; it will be important to compare our results with future utilization to see if these changes are having their intended effect of reimbursing practices for the important care they provide to patients with multiple chronic conditions in between office visits.

\section{Acknowledgements:}

We thank Rosa R. Baier, MPH, and Daniel Harris, MPH, for their insightful feedback on earlier versions of the manuscript.

Prior presentation: We presented an earlier version of these results as a poster at the Society of General Internal Medicine Annual Meeting in Washington, DC, in April 2017.

Corresponding Author: Rebekah L. Gardner, MD; Department of Medicine, Alpert Medical School of Brown University, Providence, RI, USA (e-mail: Rebekah_Gardner@Brown.edu).

Funding This study was funded by Contract Number HHSM500-2014-QINO14I, titled Excellence in Operations and Quality Improvement, sponsored by the Centers for Medicare \& Medicaid Services (CMS), an agency of the US Department of Health and Human Services. The content of this publication does not necessarily reflect the views or policies of the Department of Health and Human Services, nor does mention of trade names, commercial products, or organizations imply endorsement by the US government. CMS reviewed the manuscript and provided comments, but did not have any role in the design and conduct of the study; collection, management, analysis, or interpretation of the data; or preparation or approval of the manuscript. The authors assume full responsibility for the accuracy and completeness of the ideas presented.

\section{Compliance with Ethical Standards:}

Conflict of Interest: The authors declare that they do not have a conflict of interest.

\section{REFERENCES}

1. Sinsky C, Colligan L, Li L, Prgomet M, Reynolds S, Goeders L, Westbrook J, Tutty M, Blike G. Allocation of Physician Time in Ambulatory Practice: A Time and Motion Study in 4 Specialties. Ann Intern Med. 2016; 165 (11):753-760.

2. Gottschalk A. Flocke SA. Time Spent in Face-to-Face Patient Care and Work Outside the Examination Room. Ann Fam Med. 2005; 3(6):488-93.

3. Dyrbye LN, West CP, Burriss TC, Shanafelt TD. Providing Primary Care in the United States: The Work No One Sees. Arch Intern Med. 2012; 172 (18): 1420-1421.

4. Zlateva I, Anderson D, Coman E, Khatri $\mathbf{K}$, Tian $\mathbf{T}$, Fifield $\mathbf{J}$. Development and Validation of the Medical Home Care Coordination Survey for Assessing Care coordination in the Primary Care Setting from the Patient and Provider Perspectives. BMC Health Serv Res 2015; 15:226.

5. Kurichi JE, Pezzin L, Streim JE, Kwong PL, Na L, Bogner HR, Xie D, Hennessy S. Perceived Barriers to Healthcare and Receipt of Recommended Medical Care Among Elderly Medicare Beneficiaries. Arch Gerontol Geriatr 2017; 72:45-51.

6. Doerr E, Galpin K, Jones-Taylor C, Anander S, Demosthenes C, Platt S, Ponkshe S. Between-Visit Workload in Primary Care. J Gen Intern Med 2010; 25 (12):1289-92.

7. Pedowitz EJ, Ornstein KA, Farber J, DeCherrie LV. Time Providing Care Outside Visits in a Home-Based Primary Care Program. J Am Geriatr Soc 2014; 62(6): 1122-6.

8. Department of Health and Human Services. Chronic Care Management Services. https://www.cms.gov/Outreach-and-Education/Medicare-Learning-Network-MLN/MLNProducts/Downloads/ChronicCareManagement. pdf. Accessed April 19, 2018.

9. American College of Physicians. Chronic Care Management Tool Kit: What Practices Need to Do to Implement and Bill CCM Codes. https:// www.acponline.org/system/files/documents/running_practice/payment_coding/medicare/chronic_care management toolkit.pdf. Accessed April 19, 2018.

10. Department of Health and Human Services. Physician Fee Schedule CY 2017, Final Rule. https://federalregister.gov/d/2016-26668. Accessed April 19, 2018. 
11. Schurrer J, O'Malley AS, Wilson C, McCall N, Jain N. Evaluation of the Diffusion and Impact of the Chronic Care Management (CCM) Services: Final Report. Washington, DC: Mathematica Policy Research; 2017.

12. Department of Health and Human Services. Chronic Care Management Services Changes for 2017. https://www.cms.gov/Outreach-and-Education/Medicare-Learning-Network-MLN/MLNProducts/Downloads / ChronicCareManagementServicesChanges2017.pdf. Accessed April 19, 2018.

13. Department of Health and Human Services. CCM Health Care Professional Toolkit. https://www.cms.gov/About-CMS/Agency-Information/ OMH/Downloads/connected-hcptoolkit.pdf. Accessed April 19, 2018

14. Centers for Medicare \& Medicaid Services. Chronic Conditions Data Warehouse. CCW Condition Algorithms. https://www.ccwdata.org/web/ guest/condition-categories. Accessed April, 192018

15. Goodman RA, Posner SF, Huang ES, Parekh AK, Koh HK. Defining and Measuring Chronic Conditions: Imperatives for Research, Policy, Program, and Practice. Prev Chronic Dis 2013;10:120239.

16. Lochner KA, Goodman RA, Posner S, Parekh A. Multiple Chronic Conditions Among Medicare Beneficiaries: State-level Variations in Prevalence, Utilization, and Cost. Medicare Medicaid Res Rev 2013; 3(3):E1-19.

17. Abergel A, Rotily M, Branchoux S, Akremi R, de Léotoing L, Vainchtock A, Gaudin AF. Chronic Hepatitis C: Burden of Disease and Cost Associated with Hospitalisations in France in 2012 (The HEPCLONE study). Clin Res Hepatol Gastroenterol 2016; 40(3):340-8.

18. Bergh S, Hjorthøj C, Sørensen HJ, Fagerlund B, Austin S, Secher RG Jepsen JR, Nordentoft M. Predictors and Longitudinal Course of Cognitive Functioning in Schizophrenia Spectrum Disorders, 10 Years After Baseline: The OPUS Study. Schizophr Res 2016; 175 (1-3):57-63.

19. Cloutier M, Aigbogun MS, Guerin A, Nitulescu R, Ramanakumar AV, Kamat SA, DeLucia M, Duffy R, Legacy SN, Henderson C, Francois C, Wu E. The Economic Burden of Schizophrenia in the United States in 2013. J Clin Psychiatry 2016; 77(6):764-71.

20. Golabi P, Otgonsuren M, Suen W, Koenig AB, Noor B, Younossi ZM. Predictors of Inpatient Mortality and Resource Utilization for the Elderly Patients with Chronic Hepatitis C $(\mathrm{CH}-\mathrm{C})$ in the United States. Medicine (Baltimore). 2016; 95(3):e2482.

21. Kramer JR, Davila JA, Miller ED, Richardson P, Giordano TP, El-Serag HB. The Validity of Viral Hepatitis and Chronic Liver Disease Diagnoses in Veterans Affairs Administrative Databases. Aliment Pharmacol Ther 2008; 27(3):274-82.

22. Le Querrec F, Bounes V, Mestre ML, Azema O, Longeaux N, Gallart JC. Sex and Age Differences in ED Patients with Mental and Behavioral Disorders Due to Psychoactive Substance Use. Am J Emerg Med 2015; 33 (11): 1612-6.

23. Lin A, Di Prinzio P, Young D, Jacoby $\mathbf{P}$, Whitehouse A, Waters $\mathbf{F}$, Jablensky A, Morgan VA. Academic Performance in Children of Mothers with Schizophrenia and Other Severe Mental Illness, and Risk for Subsequent Development of Psychosis: A Population-Based Study. Schizophr Bull 2017; 43(1):205-213.

24. Mahajan R, Moorman AC, Liu SJ, Rupp L, Klevens RM; Chronic Hepatitis Cohort Study (CHeCS) Investigators. Use of the International Classification of Diseases, 9th revision, Coding in Identifying Chronic Hepatitis B Virus Infection in Health System Data: Implications for National Surveillance. J Am Med Inform Assoc 2013; 20(3):441-5.

25. Nagels A, Fährmann P, Stratmann M, Ghazi S, Schales C, Frauenheim M, Turner L, Hornig T, Katzev M, Müller-Isberner R, Grosvald M, Krug A, Kircher T. Distinct Neuropsychological Correlates in Positive and Negative Formal Thought Disorder Syndromes: The Thought and Language Disorder Scale in Endogenous Psychoses. Neuropsychobiology 2016; 73(3):139-47.

26. Schendel DE, Overgaard M, Christensen J, Hjort L, Jørgensen M, Vestergaard M, Parner ET. Association of Psychiatric and Neurologic Comorbidity with Mortality Among Persons with Autism Spectrum Disorder in a Danish Population. JAMA Pediatr 2016; 170(3):243-50.

27. Zerbo O, Yoshida C, Gunderson EP, Dorward $\mathbf{K}$, Croen LA. Interpregnancy Interval and Risk of Autism Spectrum Disorders. Pediatrics 2015 ; 136(4):651-7.

28. Heslin KC, Elixhauser A, Steiner CA. Hospitalizations Involving Mental and Substance Use Disorders Among Adults, 2012. HCUP Statistical Brief \#191. June 2015. Agency for Healthcare Research and Quality, Rockville, MD.

29. Smartlink Health. National Survey on Medicare Chronic Care Management Program Reveals Strong Interest Among Physicians, But Also Confusion. http://www.smartlinkhealth.com/wp-content/uploads/
2015/12/CCM-Market-Research-Report-Infographic-PNG.png. Accessed April 19, 2018.

30. American College of Physicians. Comments to CMS on the proposed rule for CY 2017 to revise the Medicare Physician Fee Schedule and Part B. https://www.acponline.org/acp_policy/letters/acp_comments_on_ 2017_pfs proposed rule_2016.pdf. Accessed April 19, 2018.

31. Robeznieks, Andis. Why Most Docs Skip Medicare's Chronic-Care Management Fee (And How Some are Making It Work). Modern Healthcare. October 17, 2015. http://www.modernhealthcare.com/article/20151017/MAGAZINE/310179987. Accessed April 19, 2018.

32. Oliverez, M. Chronic Care Management Reimbursement: Why Aren't More Doctors Billing for It?. MD Magazine. January 2017. http://www. mdmag.com/physicians-money-digest/practice-management/chroniccare-management-reimbursement-why-arent-more-doctors-billing-for-it. Accessed April 19, 2018.

33. Centers for Medicare \& Medicaid Services. Medicare Program; MeritBased Incentive Payment System (MIPS) and Alternative Payment Model (APM) Incentive Under the Physician Fee Schedule, and Criteria for Physician-Focused Payment Models. Final Rule: https://www. federalregister.gov/documents/2016/11/04/2016-25240/medicareprogram-merit-based-incentive-payment-system-mips-and-alternativepayment-model-apm. Accessed April 19, 2018.

34. Basu S, Phillips RS, Bitton A, Song Z, Landon BE. Medicare Chronic Care Management Payments and Financial Returns to Primary Care Practices: A Modeling Study. Ann Intern Med 2015; 163(8):580-8.

35. The Revolving Door: A Report on U.S. Hospital Readmissions. The Robert Wood Johnson Foundation. February 2013. http://www.rwjf.org/content/dam/farm/reports/reports/2013/rwjf404178. Accessed April 19, 2018.

36. Goodman DC, Esty AR, Fisher ES, Chang C-H. Trends and Variation in End-of-Life Care for Medicare Beneficiaries with Severe Chronic Illness. The Dartmouth Institute for Health Policy and Clinical Practice. April 2011. http://www.dartmouthatlas.org/downloads/reports/EOL_Trend_ Report_0411.pdf. Accessed April 19, 2018.

37. Medicare Service Use: Skilled Nursing Facilities, 2014. Kaiser Family Foundation. http://www.kff.org/medicare/state-indicator/skilled-nursing-facilities $/$ ?currentTimeframe=0\&sortModel=\%7B $\% 22$ colld $\% 22: \% 22$ Location\%22,\%22sort\%22:\%22asc\%22\%7D. Accessed April 19, 2018.

38. Community Hospitals at a Crossroads: Findings from an Examination of the Massachusetts Health Care System. Massachusetts Health Policy Commission. March 2016. http://www.mass.gov/anf/budget-taxes-and-procurement/oversight-agencies/health-policy-commission/publications/community-hospitals-at-a-crossroads.pdf. Accessed April 19, 2018.

39. Faigle R, Urrutia VC, Cooper LA, Gottesman RF. Individual and System Contributions to Race and Sex Disparities in Thrombolysis Use for Stroke Patients in the United States. Stroke 2017; 48(4):990-997.

40. Lakhter V, Zack CJ, Brailovsky Y, Chatterjee S, Aggarwal V, Rao KA, Crabbe D, Zhao H, Choi E, Kolluri R, Bashir $\mathbf{R}$. Sex differences in Utilization and Outcomes of Catheter-directed Thrombolysis in Patients with Proximal Lower Extremity Deep Venous Thrombosis-Insights from the Nationwide Inpatient Sample. Vasc Med 2017; 22(2):128-134.

41. Mulcahy A, Mehrotra A, Edison K, Uscher-Pines L. Variation in Dermatologist Visits by Sociodemographic Characteristics. J Am Acad Dermatol 2017; 76(5):918-924.

42. Yasaitis LC, Pajerowski W, Polsky D, Werner RM. Physicians' Participation In ACOs Is Lower In Places With Vulnerable Populations Than In More Affluent Communities. Health Aff (Millwood) 2016; 35(8):1382-90.

43. Reschovsky JD, O'Malley AS. Do Primary Care Physicians Treating Minority Patients Report Problems Delivering High-quality Care? Health Aff (Millwood) 2008; 27(3):w222-31.

44. Artiga S, Foutz J, Cornachione E, Garfield R. Report: Key Facts on Health and Health Care by Race and Ethnicity. Kaiser Family Foundation. June 2016. http://files.kff.org/attachment/Chartpack-Key-Factson-Health-and-Health-Care-by-Race-and-Ethnicity. Accessed April 19, 2018.

45. Health Care Spending and the Medicare Program. Medicare Payment Advisory Commission (MedPAC). June 2017. http://www.medpac.gov/ docs/default-source/data-book/jun17_databookentirereport_sec.pdf? sfvrsn=0. Accessed April 19, 2018.

46. Pham HH, Schrag D, O'Malley AS, Wu B, Bach PB. Care Patterns in Medicare and Their Implications for Pay for Performance. N Engl J Med 2007;356(11):1130-9.

47. O'Malley AS, Sarwar R, Keith R, Balke P, Ma S, McCall N. Provider Experiences with Chronic Care Management (CCM) Services and Fees: A Qualitative Research Study. J Gen Intern Med 2017;32(12):1294-1300. 